\title{
Relação de poder entre cônjuges e representações sociais das estratégias de influência no casal
}

Power Relations between Spouses and Social Representations of Influence

Strategies amongst Couples

Relation de pouvoir entre conjoints et représentations sociales des stratégies

d'influence au sein du couple

\section{Gabrielle Poeschl}

\section{(2) OpenEdition}

\section{Journals}

Edição electrónica

URL: http://journals.openedition.org/rccs/6482

DOI: $10.4000 /$ rccs. 6482

ISSN: 2182-7435

\section{Editora}

Centro de Estudos Sociais da Universidade de Coimbra

\section{Edição impressa}

Data de publição: 1 Dezembro 2016

Paginação: 109-132

ISSN: 0254-1106

\section{Refêrencia eletrónica}

Gabrielle Poeschl, «Relação de poder entre cônjuges e representações sociais das estratégias de influência no casal », Revista Crítica de Ciências Sociais [Online], 111 | 2016, colocado online no dia 07 dezembro 2016, criado a 19 abril 2019. URL : http://journals.openedition.org/rccs/6482 ; DOI $10.4000 /$ rccs. 6482

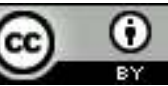




\title{
GABRIELLE POESCHL
}

\section{Relação de poder entre cônjuges e representações sociais das estratégias de influência no casal}

\begin{abstract}
A relação de poder no casal constitui um objeto de difícil abordagem pela falta de consenso sobre a definição de poder familiar e os enviesamentos constatados nos estudos baseados em autorrelatos de tomada de decisão. Num estudo conduzido com recurso a um questionário com escalas de opinião, procurou evidenciar-se a relação de poder no casal através dos comportamentos considerados apropriados em caso de desacordo entre cônjuges, pedindo-se a 384 adultos casados dos dois sexos que indicassem a probabilidade de um marido e uma esposa recorrerem a um conjunto de estratégias de influência quando tentassem impor o seu ponto de vista. Os resultados revelam uma preferência por estratégias brandas e uma grande semelhança nas estratégias adotadas pelos cônjuges, mas sugerem que as mulheres precisam de fazer um maior uso das diversas estratégias para conseguir influenciar os maridos.
\end{abstract}

Palavras-chave: estratégias de influência; papéis conjugais; relações de poder; representações de género; tomada de decisão.

\section{Introdução}

O poder, e em particular o poder na família, apesar de estudado pelos psicólogos sociais há mais de meio século continua a ser um dos conceitos que se revelam de mais difícil definição e medição (Webster, 1998). A relação de poder entre cônjuges foi analisada através dos resultados, relatados ou observados, das tomadas de decisões familiares, da importância dos recursos trazidos para a família e disponíveis pelos cônjuges para impor as suas preferências ou, ainda, através da capacidade de obter os resultados desejados recorrendo a diversas estratégias de influência.

A teoria das representações sociais defende que os comportamentos das pessoas são justificados e orientados pelas representações veiculadas nos grupos sociais a que as pessoas pertencem (Doise, 1985 e 1990; Moscovici, 1976; Poeschl, 2003). No quadro da organização familiar foi mostrado, por exemplo, que as práticas adotadas pelos cônjuges podiam ser preditas pelas representações que faziam das práticas dos outros (Poeschl, 2000) 
e eram justificadas pelas suas representações dos papéis de género (Poeschl et al., 2004). Mais concretamente, um estudo realizado em Portugal mostrou que a tomada de decisão se dividia entre os cônjuges em função de domínios específicos, sendo as decisões relativas ao lazer e ao orçamento da competência dos maridos e as decisões relativas ao lar e aos filhos da competência das mulheres, e que esta organização podia ser predita pelas representações da divisão do poder de decisão nos outros casais da mesma geração (Poeschl, 2000).

$\mathrm{Na}$ sequência deste estudo decidiu-se identificar as representações das estratégias de influência utilizadas pelos casais heterossexuais em caso de desacordo acerca de decisões familiares. Estas representações, que portanto deveriam refletir e orientar as estratégias efetivamente adotadas pelas pessoas, deveriam fornecer informações complementares sobre a relação de poder entre cônjuges. Antes de apresentar os resultados deste estudo, referimos brevemente os principais trabalhos sobre a tomada de decisão na família, as bases do poder familiar e as estratégias de influência utilizadas por homens e mulheres.

\section{Tomada de decisão e poder familiar}

O estudo do poder na família incidiu, inicialmente, na tomada de decisão (por exemplo, quem decide que carro comprar ou para onde ir de férias). De acordo com a teoria dos recursos (Blood e Wolfe, 1960), o poder era distribuído entre marido e mulher com base nos recursos que traziam para a família (dinheiro, prestígio profissional e/ou educação), o que levava os homens a ter a última palavra em muitas decisões. Apoiando esta teoria, os estudos conduzidos nos anos 1970 constataram que o ingresso das mulheres no mercado de trabalho se tinha traduzido numa menor autoridade por parte dos maridos e numa partilha mais igualitária da tomada de decisão (Blumstein e Schwartz, 1983; Scanzoni, 1977).

Estes primeiros estudos foram, contudo, alvo de críticas. Por um lado, sublinhou-se que uma definição do poder familiar em termos de tomada de decisão constitui uma definição restrita do poder (Safilios-Rothschild, 1970); por outro, foram evidenciados diversos problemas metodológicos. Salientou-se, nomeadamente, que os estudos baseados em autorrelatos de tomada de decisão induzem respostas que tendem a ocultar as desigualdades entre maridos e mulheres e não correspondem, portanto, ao comportamento efetivo dos cônjuges (Gray-Little e Burks, 1983); que o estatuto das mulheres afeta apenas algumas decisões (Michel, 1972); que os cônjuges podem não estar interessados em tomar alguns tipos de decisões (Kellerhals et al., 1993) ou, ainda, que as decisões adotadas não revelam as estratégias de poder utilizadas pelos cônjuges (Babcock et al., 1993). 
Na perspetiva de Kellerhals et al. (1993), as tomadas de decisão constituem apenas um dos níveis do poder familiar. As tomadas de decisão situam-se ao nível da atribuição dos recursos, nível em que cada cônjuge pode gerir à vontade os recursos destinados à zona de competência que lhe é confiada (ver, por exemplo, Poeschl, 2000). Porém, sempre segundo Kellerhals et al. (1993), a repartição das zonas de competência entre os dois cônjuges e a decisão sobre a importância dos recursos destinados a cada zona de competência são decididas a um outro nível, o nível da determinação dos recursos, no qual a autoridade masculina permanece intocável. Por conseguinte, mesmo quando o poder parece dividido mais ou menos igualitariamente entre marido e mulher, devido ao facto de os cônjuges serem responsáveis por diferentes esferas de competência ao nível das decisões quotidianas, a autoridade dos homens fica intacta ao nível mais elevado do poder familiar.

Dado que as decisões tomadas não informam sobre quem decidiu a repartição das zonas de competência nem sobre quem designou a pessoa habilitada a decidir esta repartição, ficou claro que o mero estudo da tomada de decisão na família não podia constituir uma medida válida do poder familiar (Safilios-Rothschild, 1970). A investigação que relaciona o poder familiar com a tomada de decisão passou, portanto, a tomar em consideração, ainda, a estrutura do poder familiar (as suas bases) e os processos de poder, para além dos seus resultados, como sugerido pelas perspetivas multidimensionais do poder (Cromwell e Olson, 1975).

\section{Recursos e poder familiar}

Diferenciando-se de uma definição do poder familiar enquanto tomada de decisão, alguns autores analisaram os fatores suscetíveis de explicar como uma pessoa (o agente de influência) tem o potencial para influenciar uma outra (o alvo de influência). Referindo as cinco bases do poder (legítimo, de perícia, de referência, coercivo, e de recompensa) identificadas por French e Raven (1959), Hallenbeck (1966) desenvolveu uma tipologia do poder familiar. Nesta perspetiva, um parceiro pode controlar o comportamento do outro porque o outro considera que o parceiro tem o direito de exercer esse controlo (poder legítimo), tem mais conhecimentos e competências (poder de perícia), porque o outro se identifica com o parceiro (poder de referência) ou, ainda, porque o parceiro tem a possibilidade de distribuir recompensas (poder de recompensa) ou infligir castigo (poder coercivo). O medo de ser desaprovado, tal como o desejo de ser aprovado, constituem também importantes fontes do poder coercivo ou de recompensa (Safilios-Rothschild, 1970).

A análise das bases do poder familiar realçou assim que, para além da falta de fundamentação existente para restringir o poder familiar à tomada 
de decisão, as fontes do poder na família não estão limitadas aos recursos materiais. Rodman (1972), em particular, defendeu que, para além dos recursos materiais que os cônjuges possuem, as normas relativas aos papéis de género exercem um efeito importante sobre a relação de poder entre cônjuges, variando o poder legítimo do marido consoante o grau de tradicionalismo dos casais.

Para evidenciar as diferenças entre casais tradicionais e casais progressistas, Kulik (1999) examinou, numa amostra masculina, o peso relativo de diversos recursos incluindo, para além dos recursos económicos, recursos intangíveis, tais como recursos sociais, de saúde, psicológicos e afetivos. A autora verificou que, para além dos recursos económicos e sociais tradicionalmente masculinos, os sentimentos constituíam uma poderosa fonte de poder feminino nos casais mais tradicionalistas. Na relação de poder dos casais mais progressistas, várias capacidades psicológicas femininas também moderavam a relação. De facto, os resultados dos estudos sobre as bases do poder familiar apontaram para a existência de um vasto leque de recursos intangíveis como a atratividade, a inteligência, ou qualquer outro aspeto valorizado (Safilios-Rothschild, 1970).

\section{Recursos e tomada de decisão}

Apesar de reconhecer que, teoricamente, as bases do poder não estão limitadas aos recursos materiais, muitos estudos sobre a tomada de decisão analisaram o efeito dos rendimentos dos cônjuges. Alguns autores encontraram uma relação positiva entre o poder económico dos cônjuges e o seu controlo sobre o dinheiro (Pahl, 1989), enquanto outros sugeriram que, independentemente do contributo das mulheres para o rendimento familiar, os maridos continuam a exercer o controlo sobre o dinheiro e outras decisões familiares (Tichenor, 1999). Concluiu-se que havia uma relação entre os vencimentos e a tomada de decisão dos maridos, mas não das mulheres.

Os autores que se interessaram pela falta de relação entre o rendimento das mulheres e o seu poder na família mostraram que o efeito do ordenado feminino dependia da necessidade atribuída pelo marido ao vencimento da mulher (Blumberg e Coleman, 1989). Por sua vez, os estudos sobre os casais não convencionais revelaram que os homens e as mulheres aceitam com relutância que as mulheres sejam as principais fontes de rendimento da família (Deutsch et al., 2003). Para provarem que não procuram dominar os maridos e não perderam a sua feminilidade, muitas vezes as mulheres que ganham mais do que os maridos envolvem-se pouco nas tomadas de decisão (Tichenor, 2005). 
Este comportamento ilustra uma outra perspetiva sobre o poder. Nesta perspetiva, o poder tanto pode corresponder à capacidade de produzir os efeitos desejados através de uma ação intencional, como ao facto de alguns indivíduos ou grupos verem os seus interesses respeitados e as suas preferências aceites, sejam eles ativos ou não (Lukes, 2007). Mais precisamente, Lukes (1974) distingue três facetas do poder: manifesto, latente e invisível. O poder manifesto é observável nos resultados da tomada de decisão e revela-se quando surgem conflitos. O poder latente permite, a quem o possui, impedir o surgimento de conflitos ou tentativas de mudança, causando resignação em virtude do medo de reações negativas. O poder invisível está baseado nas construções ideológicas que apresentam algum tipo de dominação como natural e desejável, tornando os conflitos irrelevantes (Lukes, 2007). Esta perspetiva tridimensional do poder leva à conclusão paradoxal de que o poder é tanto mais efetivo quanto menos observável.

Aplicando esta perspetiva ao estudo do poder nas relações conjugais, Komter (1989) constatou que as formas de expressão do poder manifesto eram mais frequentes nos casais das classes mais elevadas, ao passo que as manifestações do poder latente eram mais aparentes nos casais das classes mais baixas. Por sua vez, o poder invisível era uma resposta mais adequada à ameaça que constituem as desigualdades entre maridos e mulheres nos casais de classes elevadas, mais igualitaristas. Em suma, o poder masculino na família seria preservado em virtude das expetativas generalizadas de que os maridos detêm mais poder (Felmlee, 1994), sendo as relações em que os maridos não dominam pouco aceites socialmente e pouco satisfatórias para ambos os cônjuges (Gray-Little e Burks, 1983).

Verificou-se, assim, que a necessidade de se conformar aos papéis de género masculino e feminino constitui uma base importante do poder familiar. Inferiu-se que a influência dos papéis de género também devia transparecer nos processos que determinam as decisões tomadas na família, levando a diferenças nas estratégias dos cônjuges para influenciar estas decisões (Babcock et al., 1993).

\section{Estratégias de influência e poder familiar}

O estudo das estratégias de influência encontrou uma primeira dificuldade quando se procurou repertoriá-las e organizá-las em taxinomias: alguns autores procuraram dimensões subjacentes às estratégias e dividiram-nas em estratégias distintas nessa dimensão, por exemplo, duras vs. brandas, ou racionais vs. irracionais (ver Perloff, 2003). Outros procuraram grupos (ou "clusters") de táticas que respondem a um mesmo princípio organizador (ver Cialdini, 2001) e outros ainda procuraram estabelecer listas de estratégias (Falbo, 1977). Existem assim 
propostas que distinguem dois grandes grupos de estratégias e outras que repertoriam dezenas de táticas diferentes.

Os estudos que compararam as estratégias de influência utilizadas pelos homens e pelas mulheres concluíram que as estratégias indiretas e manipuladoras - impotência, simpatia - seriam tipicamente femininas, enquanto as estratégias diretas - coerção, negociação - seriam tipicamente masculinas (Instone et al., 1983). As explicações fornecidas apontaram para o efeito da socialização (Gagnon e Simon, 1973) ou para as desigualdades sociais, políticas e económicas que facilitam o acesso dos homens aos recursos do poder (Falbo e Peplau, 1980). Os homens utilizariam, assim, táticas originadas no maior poder que eles detêm na sociedade, enquanto as mulheres utilizariam táticas que lhes permitiriam compensar a sua falta de poder (Cataldi e Reardon, 1996).

Apoiando as explicações baseadas nas diferenças efetivas de poder, os estudos que se centraram sobre as táticas utilizadas pelos homens e pelas mulheres nas organizações revelaram que os dois sexos apresentavam apenas ténues diferenças quando beneficiavam do mesmo estatuto e dispunham de recursos equivalentes (Instone et al., 1983). As poucas diferenças observadas deviam-se aparentemente ao facto de os homens terem, geralmente, mais autoconfiança do que as mulheres.

No contexto das relações íntimas, alguns autores encontraram diferenças entre as estratégias utilizadas pelos homens e pelas mulheres: os homens diziam utilizar mais estratégias bilaterais e diretas, enquanto as mulheres diziam adotar mais estratégias unilaterais e indiretas (Falbo e Peplau, 1980). Os homens pareciam também atribuir mais importância ao facto de terem influência, enquanto as mulheres se declaravam mais igualitaristas e percecionavam a relação como mais igualitária. Estes resultados foram explicados pelas diferenças de poder entre os homens e as mulheres, que levavam os homens a esperar obediência e as mulheres a recorrer a estratégias que não necessitam da cooperação do parceiro.

Outros autores, no entanto, constataram uma ausência de diferenças entre os dois grupos sexuais e uma forte reciprocidade de comportamentos nos casais (Buss et al., 1987). Weigel et al. (2006; ver também Cataldi e Reardon, 1996) observaram que, apesar da grande reciprocidade de comportamentos entre cônjuges, as mulheres com níveis inferiores de intimidade relacional ou com menor perceção do seu poder na relação eram suscetíveis de fazer um uso mais frequente de estratégias de influência indiretas. Por último, alguns autores sugeriram que os casais com dupla carreira se envolviam num maior número de tentativas de influência do que os casais que assumiam uma única carreira (Sexton e Perlman, 1989); ou ainda que, por causa da sua 
posição dominada, as mulheres necessitavam de recorrer a mais estratégias para conseguir influenciar os maridos (Aida e Falbo, 1991).

Em suma, dado que o sexo e os papéis de género reportam inevitavelmente a diferenças de estatuto, torna-se difícil desligar as estratégias de influência no casal da relação de poder entre cônjuges (Sagrestano, 1992).

\section{Objetivos e hipóteses}

O nosso estudo procurou compreender o modo como adultos casados dos dois sexos representam as estratégias de influência utilizadas pelos cônjuges em situação de desacordo, partindo do princípio que estas estratégias informam sobre a relação de poder entre cônjuges e que os comportamentos efetivos das pessoas são orientados pelas suas representações dos comportamentos adequados (Poeschl, 2003).

Foram consideradas três condições: a) uma condição indefinida, em que o desfecho do desacordo não era conhecido; b) uma condição em que a opinião do marido era adotada; c) uma condição em que a opinião da esposa era adotada. Partimos do pressuposto que os homens são ainda considerados como os chefes de família e têm mais poder nas tomadas de decisão (Tichenor, 1999), mas que existem zonas de competência que podem ser atribuídas a cada cônjuge (Kellerhals et al., 1993). Portanto, duas situações de desacordo foram contempladas: a) uma situação de desacordo acerca da escolha entre um carro ou um cheque, mais relacionada com a zona de competência masculina; b) uma situação de desacordo acerca da escolha entre dois tipos diferentes de mobiliário de cozinha, mais relacionada com a zona de competência feminina (Poeschl, 2000).

Finalmente, considerando a diferença classicamente encontrada na literatura entre o processo que visa a aceitação e o processo que visa a submissão (Perloff, 2003), procurámos saber em que medida os respondentes consideravam que cada cônjuge procurava persuadir ou obrigar o parceiro a aceitar a sua escolha.

Foram colocadas cinco hipóteses:

H1: De acordo com a literatura (Instone et al., 1983), a esposa será vista como o cônjuge que mais recorre a estratégias indiretas e o marido como o cônjuge que mais recorre a estratégias diretas.

$\mathrm{H} 2$ : Em conformidade com os estudos que realçam o habitual acordo entre homens e mulheres acerca das diferenças entre os sexos (Eagly, 1995) não haverá diferenças significativas entre as respostas dos homens e as respostas das mulheres.

H3: Na condição menos típica em que a esposa ganha (Tichenor, 1999), o marido será descrito como tendo recorrido menos a todos os tipos de estratégias. 
H4: Tendo em conta que existem zonas de competência masculinas e femininas (Kellerhals et al., 1993), o envolvimento do marido será menor quando a situação de desacordo pertence à zona de competência feminina.

H5: Dado que, de acordo com a literatura, é esperado que os maridos tenham mais poder do que as mulheres na família (Felmlee, 1994), de forma geral o marido será visto como tendo mais intenções de obrigar do que a esposa, e a esposa como tendo mais intenções de persuadir do que o marido.

\section{Método}

\section{Respondentes}

Os respondentes são 384 adultos casados da região do Porto, 192 homens e 192 mulheres com uma idade média de 43 anos e, em média, dois filhos. No que diz respeito à profissão, $77 \%$ dos respondentes masculinos são independentes ou quadros, $22,5 \%$ são empregados ou operários e um respondente $(0,5 \%)$ é reformado. $68 \%$ dos respondentes femininos são independentes ou quadros, $15 \%$ são empregadas ou operárias, $14 \%$ são donas de casa e $3 \%$ reformadas. Relativamente à religião, $93 \%$ dos respondentes são católicos (mas apenas $40 \%$ são praticantes) e todas as orientações políticas são representadas, sendo a tendência de esquerda a mais frequente (38\%).

\section{Questionário}

Cada questionário começava pela apresentação de uma de duas situações de desacordo. A primeira situação era a seguinte: "A Luísa e o Paulo são um jovem casal de professores com dois filhos. Entraram, por curiosidade, num concurso televisivo e foram surpreendidos ao vencerem a final. As coisas complicaram-se quando tiveram que escolher o prémio: tratava-se de receber ou um automóvel ou um cheque de igual valor monetário. O Paulo preferia o automóvel, último modelo de uma marca prestigiada, enquanto a Luísa preferia o cheque, o qual lhes permitiria gozar de uma certa segurança financeira". O texto terminava de forma diferente consoante as condições experimentais. $\mathrm{Na}$ condição "desfecho desconhecido", os respondentes eram informados de que "o casal teve uma semana para comunicar a sua decisão". Nas duas outras condições, a frase era completada por, respetivamente, "que foi aceitar o carro" (o marido ganha) ou "que foi aceitar o cheque" (a mulher ganha).

A segunda situação apresentava apenas ligeiras diferenças. No concurso televisivo os cônjuges ganhavam "o segundo prémio" e tratava-se de "um mobiliário de cozinha completo, de preço elevado. Havia dois modelos de móveis diferentes à escolha, ambos de excelente qualidade e com o mesmo preço. O problema era que, enquanto o Paulo queria escolher um mobiliário muito atraente de linhas modernas (o modelo Cozibela), a Luísa preferia 
um outro, menos atraente, mas que ela achava mais apropriado para a cozinha (o modelo Modular)." O texto acabava de forma semelhante ao primeiro. As duas situações de desacordo foram escolhidas por serem, num estudo anterior (Poeschl, 2000), as mais caraterísticas, respetivamente, da zona de competência masculina e da zona de competência feminina.

Os respondentes deviam de seguida indicar a probabilidade $(1=$ totalmente improvável; 7 = totalmente provável) de cada um dos cônjuges utilizarem (ou terem utilizado) cada uma de 32 estratégias de influência (ver Quadro 1), sempre apresentadas na mesma sequência. Estas estratégias foram selecionadas a partir da literatura. Foram tomados em consideração os quatro tipos de estratégias (bilateral-direto, bilateral-indireto, unilateral-direto e unilateral-indireto) propostos por Falbo e Peplau (1980; ver também Cataldi e Reardon, 1996). Escolheram-se, dentro destes tipos, quatro itens pertencentes a cada uma das duas categorias seguintes: negociação e argumentação (bilateral-direto); charme e manipulação consciente (bilateral-indireto); coerção e asserção (unilateral-direto); rebaixamento e tratamento silencioso (unilateral-indireto).

No fim do questionário, os respondentes deviam ainda indicar a probabilidade ( 1 = totalmente improvável; 7 = totalmente provável) de as estratégias adotadas terem por finalidade persuadir o cônjuge ou, pelo contrário, obrigá-lo a conformar-se.

As diferentes versões do questionário, equitativamente repartidas pelas condições do plano de investigação, foram distribuídas aleatoriamente entre os respondentes. Estes, que constituem uma amostra de conveniência, foram contactados pelos estudantes que participaram no estudo, e, após aceitarem participar no inquérito, preencheram individualmente o questionário que lhes foi entregue.

\section{Resultados e discussão}

\section{Tipos de estratégias}

Começámos por aplicar uma análise fatorial em componentes principais, com rotação varimax, sobre a probabilidade de os cônjuges recorrerem às 32 estratégias propostas. Depois de retirarmos seis itens que obtiveram saturações equivalentes em mais do que um fator ("pedir para deixar escolher"; "comparar o parceiro com alguém que escolheria o prémio certo"; "procurar convencer utilizando o charme"; "fazer analogias entre a atual situação e outras do passado"; "prometer deixar fazer algo se o parceiro renuncia à sua escolha"; "prometer dar qualquer coisa em troca de deixar escolher"), a análise extraiu seis fatores com valor próprio superior a um, que explicam 55,23\% da variância total. O Quadro 1 apresenta a composição 
dos componentes, as percentagens de variância explicada por cada um, assim como a consistência interna, medida pelo alfa de Cronbach, das escalas construídas a partir da solução fatorial.

QUADRO 1 - Análise fatorial em componentes principais sobre a probabilidade de os cônjuges recorrerem às diferentes estratégias de influência. Percentagem de variância explicada, saturações, valores do alfa de Cronbach

\begin{tabular}{|c|c|c|c|c|c|c|}
\hline & F1 & F2 & F3 & F4 & F5 & F6 \\
\hline & $14,06 \%$ & $11,05 \%$ & $10,64 \%$ & $7,17 \%$ & $7,07 \%$ & $5,24 \%$ \\
\hline \multicolumn{7}{|l|}{ Coerção $(\alpha=.82)$} \\
\hline $\begin{array}{l}\text { Recusar-se a fazer algo de que o parceiro gosta, } \\
\text { caso não concorde com a sua escolha }\end{array}$ & .76 & .26 & .03 & -.01 & .03 & .04 \\
\hline $\begin{array}{l}\text { Ameaçar o parceiro com algo, se este levar avante } \\
\text { a sua escolha }\end{array}$ & .72 & .06 & .02 & -.10 & .18 & .07 \\
\hline $\begin{array}{l}\text { Humilhar o parceiro em público por não concordar } \\
\text { com a sua escolha }\end{array}$ & .69 & -.07 & -.11 & -.06 & .28 & -.02 \\
\hline Criticar o parceiro por não deixar escolher & .64 & .34 & .15 & .07 & -.12 & .04 \\
\hline Ignorar o parceiro quando diz que não concorda & .60 & .12 & .04 & -.10 & .15 & .23 \\
\hline Exigir ao parceiro que renuncie à sua escolha & .56 & .03 & -.02 & .01 & .31 & .15 \\
\hline $\begin{array}{l}\text { Amuar porque o parceiro não concorda com } \\
\text { a sua escolha }\end{array}$ & .51 & .41 & .19 & .04 & .05 & .18 \\
\hline \multicolumn{7}{|l|}{ Manipulação $(\alpha=.76)$} \\
\hline $\begin{array}{l}\text { Mostrar-se carinhoso para que o parceiro deixe } \\
\text { escolher }\end{array}$ & .20 & .74 & .16 & -.03 & -.06 & .19 \\
\hline Elogiar o parceiro para que renuncie à sua escolha & .41 & .60 & -.04 & .12 & .06 & -.04 \\
\hline $\begin{array}{l}\text { Pedir com humildade que o parceiro renuncie à sua } \\
\text { escolha }\end{array}$ & -.05 & .58 & .08 & .17 & .42 & -.09 \\
\hline $\begin{array}{l}\text { Tornar-se romântico ao pedir que o parceiro } \\
\text { concorde com a sua escolha }\end{array}$ & .14 & .57 & .26 & -.05 & .19 & .08 \\
\hline Suplicar o parceiro que concorde com a sua escolha & .25 & .55 & -.04 & .13 & .37 & .08 \\
\hline $\begin{array}{l}\text { Dizer o quanto ficaria feliz se o parceiro concordasse } \\
\text { com a sua escolha }\end{array}$ & .03 & .55 & .24 & .33 & -.10 & .21 \\
\hline \multicolumn{7}{|l|}{ Argumentação ( $\alpha=.75$ ) } \\
\hline $\begin{array}{l}\text { Salientar todas as vantagens que adviriam da sua } \\
\text { escolha }\end{array}$ & .04 & .11 & .72 & .26 & -.04 & -.05 \\
\hline Explicar ao parceiro as razões da sua escolha & -.06 & .13 & .70 & .29 & -.08 & .04 \\
\hline
\end{tabular}




\begin{tabular}{|c|c|c|c|c|c|c|}
\hline & F1 & F2 & F3 & F4 & F5 & F6 \\
\hline & $14,06 \%$ & $11,05 \%$ & $10,64 \%$ & $7,17 \%$ & $7,07 \%$ & $5,24 \%$ \\
\hline $\begin{array}{l}\text { Dizer ao parceiro o quanto o prémio escolhido é } \\
\text { importante para ele }\end{array}$ & .02 & .20 & .68 & -.08 & -.01 & .13 \\
\hline $\begin{array}{l}\text { Lembrar ao parceiro que não necessitam do prémio } \\
\text { que escolheu }\end{array}$ & .11 & .04 & .65 & -.10 & .03 & -.01 \\
\hline Argumentar logicamente a favor da sua escolha & .09 & .01 & .53 & .35 & -.02 & .00 \\
\hline Perguntar ao parceiro sobre as razões da sua escolha & -.18 & .07 & .49 & .34 & .04 & -.13 \\
\hline \multicolumn{7}{|l|}{ Negociação $(\alpha=.58)$} \\
\hline $\begin{array}{l}\text { Procurar uma solução de compromisso com } \\
\text { vantagens para ambos }\end{array}$ & .08 & -.11 & .10 & .77 & -.04 & .26 \\
\hline $\begin{array}{l}\text { Propor conversar sobre o que seria melhor para } \\
\text { ambos }\end{array}$ & -.30 & .26 & .21 & .59 & .07 & -.12 \\
\hline Tentar chegar a um acordo com o parceiro & -.05 & .29 & .22 & .57 & .03 & -.18 \\
\hline \multicolumn{7}{|l|}{ Rebaixamento $(\alpha=.75)$} \\
\hline $\begin{array}{l}\text { Deixar-se humilhar pelo parceiro para que este } \\
\text { aceite a sua escolha }\end{array}$ & .26 & .10 & -.03 & -.02 & .79 & .12 \\
\hline Rebaixar-se para que o parceiro deixe escolher & .34 & .14 & -.04 & -.02 & .74 & .11 \\
\hline \multicolumn{7}{|l|}{ Tratamento silencioso $(\alpha=.43)$} \\
\hline $\begin{array}{l}\text { Não responder cada vez que o parceiro diz } \\
\text { que quer escolher }\end{array}$ & .10 & .06 & -.05 & -.02 & .20 & .79 \\
\hline $\begin{array}{l}\text { Tornar-se silencioso quando o parceiro fala } \\
\text { do prémio que prefere }\end{array}$ & .28 & .24 & .08 & .05 & -.00 & .58 \\
\hline
\end{tabular}

Apesar de não corresponder exatamente à solução fatorial prevista, os componentes extraídos apontam claramente para seis tipos de estratégias que correspondem aos quatro tipos considerados: a coerção (unilateral-direto), a manipulação (bilateral-indireto, fator que reúne o charme e a manipulação consciente), a argumentação (bilateral-direto, fator que integra também alguns itens da asserção), a negociação (bilateral-direto), o rebaixamento (unilateral-indireto) e o tratamento silencioso (unilateral-indireto).

Os itens reunidos nos fatores foram agregados para formar seis escalas. As análises de variância aplicadas sobre as médias dessas escalas para examinar as nossas hipóteses revelaram que todos os fatores contemplados tinham um efeito sobre as respostas dos inquiridos. Começamos por apresentar a probabilidade média de os cônjuges recorrerem aos seis tipos de estratégias e descrevemos, sequencialmente, os efeitos do sexo dos cônjuges descritos, do sexo de pertença dos respondentes, do desfecho e da situação de desacordo. 


\section{Probabilidade de utilização das estratégias de influência}

A probabilidade média de as estratégias de influência propostas serem utilizadas pelos dois cônjuges é descrita na Figura 1.

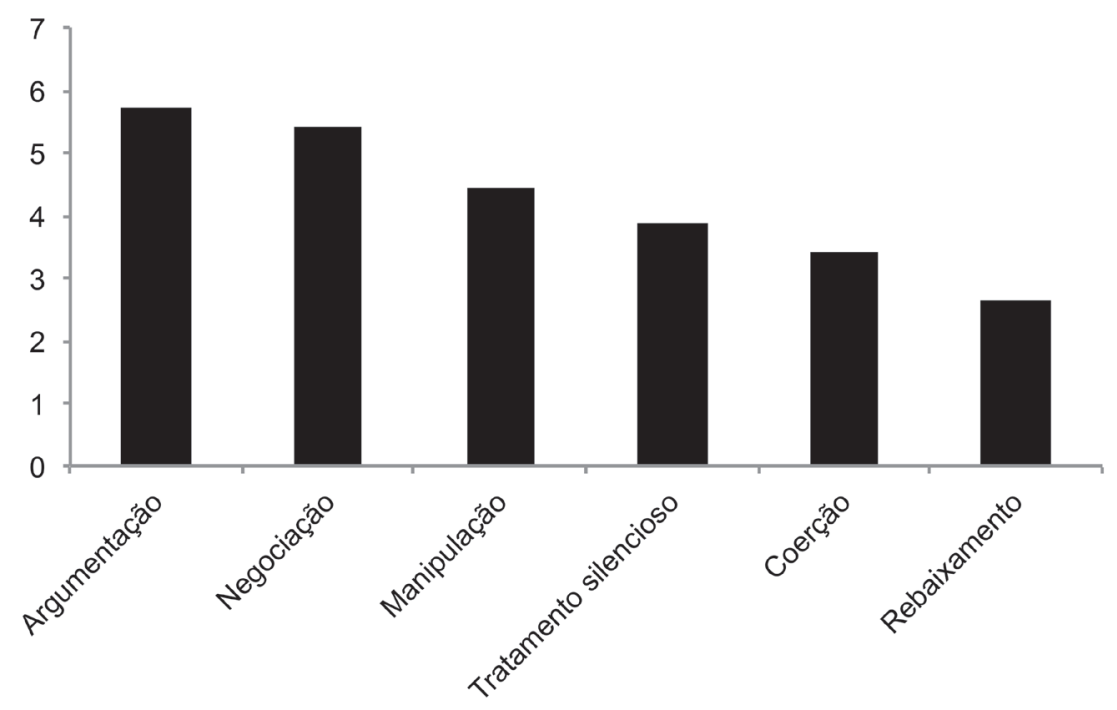

FIGURA 1 - Probabilidade média de os cônjuges recorrerem aos seis tipos de estratégias propostas ( 1 = totalmente improvável; 7 = totalmente provável)

Como se pode observar na Figura 1, há diferenças na probabilidade de os cônjuges recorrerem aos diferentes tipos de estratégias (argumentação: 5.71; negociação: 5.41; manipulação: 4.46; tratamento silencioso: 3.85; coerção: 3.41; rebaixamento: 2.63$), F(5,1860)=743.13, p<.001$. De facto, segundo o teste LSD para comparações múltiplas, todos os tipos de estratégias têm uma probabilidade diferente de serem utilizados, $p<.001$. As estratégias bilaterais, mais apropriadas para a manutenção da harmonia na relação do casal, são vistas como as mais suscetíveis de serem utilizadas enquanto as estratégias unilaterais, mais nefastas para a relação (tratamento silencioso e coerção) ou para a autoestima (rebaixamento), são as menos suscetíveis de serem utilizadas. Este resultado vai ao encontro dos resultados habitualmente referidos na literatura (Howard et al., 1986, por exemplo). 


\section{Estratégias femininas vs. estratégias masculinas}

O Quadro 2 apresenta a probabilidade média de cada um dos cônjuges recorrer aos diferentes tipos de estratégias de influência.

\section{QUADRO 2 - Probabilidade média de cada um dos cônjuges recorrer aos seis tipos de estratégias de influência \\ ( 1 = totalmente improvável; 7 = totalmente provável)}

\begin{tabular}{lccc}
\hline & $\begin{array}{c}\text { Luísa } \\
(\mathrm{n}=\mathbf{3 8 4})\end{array}$ & $\begin{array}{c}\text { Paulo } \\
(\mathrm{n}=384)\end{array}$ & Diferença \\
\hline Argumentação & 5.87 & 5.55 & $.32 \mathrm{ab}$ \\
\hline Negociação & 5.55 & 5.27 & $.27 \mathrm{~b}$ \\
\hline Manipulação & 4.66 & 4.26 & $.40 \mathrm{a}$ \\
\hline Tratamento silencioso & 3.97 & 3.72 & $.25 \mathrm{bc}$ \\
\hline Coerção & 3.49 & 3.33 & $.16 \mathrm{c}$ \\
\hline Rebaixamento & 2.78 & 2.48 & $.30 \mathrm{ab}$ \\
\hline
\end{tabular}

Nota: na última coluna, letras diferentes indicam diferenças de médias significativamente diferentes.

Pode constatar-se através do Quadro 2 que os diferentes tipos de estratégias seguem a mesma ordem de utilização, quando os participantes descrevem a Luísa ou o Paulo, apoiando a opinião de que as expetativas acerca da utilização de estratégias de influência são culturalmente definidas (cf. Sagrestano, 1992). Contudo, à Luísa atribui-se uma maior probabilidade do que ao Paulo de recorrer a cada um dos seis tipos de estratégias (todos os $p_{s}<.001$ ) e, de uma forma global, ao conjunto de estratégias (Luísa: 4.39; Paulo: 4.10), $F(1,372)=116.50, p<.001$. Este resultado sugere que os respondentes percecionam uma desigualdade de poder entre cônjuges, de acordo com o ponto da vista de que as mulheres, tendo menos poder, precisam de recorrer a um maior número de estratégias para conseguir influenciar os maridos (Aida e Falbo, 1991).

A interação significativa entre as estratégias e os cônjuges, $F(5,1860)=4.01$, $p=.001$, apenas surge da extensão das diferenças entre cônjuges: a Luísa tem sobretudo uma maior probabilidade de recorrer à manipulação do que o Paulo $(d=.40)$, o que seria consistente com a literatura (Instone et al., 1983). Contudo, o maior recurso da Luísa a todas as estratégias de influência não apoia a nossa Hipótese 1 segundo a qual a esposa será vista como o cônjuge que mais recorre a estratégias indiretas e o marido como o cônjuge que mais recorre a estratégias diretas.

Resumindo, os inquiridos consideram que há uma probabilidade mais elevada de os cônjuges utilizarem estratégias bilaterais do que unilaterais 
e que é provável que a Luísa faça um maior uso de todos os tipos de estratégias para tentar impor o seu ponto de vista.

Examinamos agora as modulações introduzidas neste padrão de respostas pelos restantes fatores contemplados.

\section{Efeito do sexo de pertença dos respondentes}

A interação entre o sexo de pertença dos respondentes, o sexo dos cônjuges descritos e os tipos de estratégias, $F(5,1860)=4.60, p<.001$, revela que o sexo de pertença modula a avaliação das estratégias de influência utilizadas pelos dois cônjuges. A probabilidade de os cônjuges recorrerem às estratégias consoante o sexo dos inquiridos está descrita no Quadro 3.

QUADRO 3 - Probabilidade média de os cônjuges recorrerem aos seis tipos de estratégias de influência consoante o sexo de pertença dos respondentes (1 = totalmente improvável; 7 = totalmente provável)

\begin{tabular}{|c|c|c|c|c|}
\hline & \multicolumn{2}{|c|}{ Homens } & \multicolumn{2}{|c|}{ Mulheres } \\
\hline & $\begin{array}{c}\text { Luísa } \\
(\mathrm{n}=192)\end{array}$ & $\begin{array}{c}\text { Paulo } \\
(\mathrm{n}=192)\end{array}$ & $\begin{array}{c}\text { Luísa } \\
(\mathrm{n}=192)\end{array}$ & $\begin{array}{c}\text { Paulo } \\
(n=192)\end{array}$ \\
\hline Argumentação & $5.74 b$ & $5.44 c$ & $6.01 a$ & $5.66 \mathrm{bc}$ \\
\hline Negociação & $5.41 b$ & $5.15 c$ & $5.68 a$ & $5.40 b c$ \\
\hline Manipulação & $4.70 a$ & $4.18 c$ & $4.62 a$ & $4.34 b$ \\
\hline Tratamento silencioso & $4.07 a$ & $3.62 b$ & $3.87 a$ & $3.82 \mathrm{ab}$ \\
\hline Coerção & $3.50 a$ & $3.25 b$ & $3.48 a$ & $3.41 \mathrm{ab}$ \\
\hline Rebaixamento & $2.89 a$ & $2.44 \mathrm{~b}$ & $2.67 a b$ & $2.51 \mathrm{ab}$ \\
\hline
\end{tabular}

Nota: em cada linha, letras diferentes indicam médias significativamente diferentes.

A decomposição da interação revela que, enquanto os homens acreditam que a Luísa apresenta uma maior probabilidade do que o Paulo de recorrer a todas as estratégias de influência, as mulheres consideram que a Luísa apenas utiliza mais do que o Paulo as estratégias bilaterais (argumentação, negociação, manipulação).

Por outro lado, as mulheres consideram mais do que os homens que a Luísa recorre às estratégias de argumentação e de negociação e os homens consideram menos do que as mulheres que o Paulo é suscetível de recorrer à manipulação.

Portanto, contrariamente à nossa Hipótese 2 , segundo a qual não haverá diferenças significativas entre as respostas dos homens e as respostas das 
mulheres, existem algumas modulações nas respostas dos inquiridos: os homens parecem concordar com o facto de que a posição dominada das mulheres as leva a recorrer a um maior número de estratégias para conseguir influenciar os maridos enquanto, contrariamente ao que se encontra na literatura, as mulheres consideram que têm uma maior probabilidade de escolher as estratégias bilaterais diretas, consideradas masculinas, do que os homens (Falbo e Peplau, 1980), sendo a manipulação vista como uma estratégia mais específica do sexo feminino.

\section{Efeito do desfecho}

A interação entre o desfecho do desacordo, o sexo dos cônjuges e os tipos de estratégias, $F(10,1860)=2.23, p=.014$, revela que o desfecho modula a avaliação das estratégias utilizadas pelos dois cônjuges, como se pode observar no Quadro 4.

QUADRO 4 - Probabilidade média de os cônjuges recorrerem aos seis tipos de estratégias de influência consoante o desfecho da situação

( 1 = totalmente improvável; 7 = totalmente provável)

\begin{tabular}{|c|c|c|c|c|c|c|}
\hline & \multicolumn{2}{|c|}{ Desconhecido } & \multicolumn{2}{|c|}{ Paulo ganha } & \multicolumn{2}{|c|}{ Luísa ganha } \\
\hline & Luísa & Paulo & Luísa & Paulo & Luísa & Paulo \\
\hline & \multicolumn{2}{|c|}{$(n=127)$} & \multicolumn{2}{|c|}{$(n=129)$} & \multicolumn{2}{|c|}{$(n=128)$} \\
\hline Argumentação & $5.95 a$ & $5.59 \mathrm{~b}$ & $5.69 b$ & $5.62 b$ & $5.97 a$ & $5.44 b$ \\
\hline Negociação & $5.75 a$ & $5.53 b$ & $5.29 b c$ & $5.18 c$ & $5.59 a$ & $5.11 \mathrm{c}$ \\
\hline Manipulação & $4.72 \mathrm{a}$ & $4.30 b c$ & $4.50 a$ & 4.39ab & $4.77 a$ & $4.10 c$ \\
\hline Tratamento silencioso & $4.07 a$ & $3.88 \mathrm{~b}$ & $3.97 a$ & $3.74 b$ & $3.87 a$ & $3.55 b$ \\
\hline Coerção & $3.79 a$ & $3.54 b$ & $3.45 b$ & $3.44 b$ & $3.24 b$ & $3.01 \mathrm{c}$ \\
\hline Rebaixamento & $2.82 \mathrm{a}$ & $2.52 \mathrm{~b}$ & $2.81 a$ & $2.61 \mathrm{ab}$ & $2.70 a$ & $2.30 \mathrm{~b}$ \\
\hline
\end{tabular}

Nota: em cada linha, letras diferentes indicam médias significativamente diferentes.

A decomposição da interação indica que, quando o desfecho não é conhecido ou quando a Luísa ganha, a Luísa é vista como tendo uma maior probabilidade do que o Paulo de usar todas as estratégias de influência. Contudo, isto não é o caso quando o Paulo ganha. Nesta situação não há diferenças na probabilidade de os cônjuges recorrerem aos diferentes tipos de estratégias, a não ser no que respeita ao tratamento silencioso, também mais utilizado nesta situação pela Luísa do que pelo Paulo. 
Comparando as estratégias atribuídas a cada cônjuge nas diferentes condições, pode observar-se ainda que os participantes descrevem a Luísa como tendo recorrido menos à argumentação e à negociação quando o Paulo ganha do que quando ela ganha; a Luísa é também vista como tendo recorrido mais às estratégias de coerção quando o desfecho não é conhecido. Por sua vez, os respondentes acreditam que o Paulo apresenta menor probabilidade de usar a manipulação e a coerção quando a Luísa ganha do que quando ele ganha; o Paulo é também visto como tendo recorrido mais às estratégias de negociação quando o desfecho não é conhecido.

Em suma, a nossa Hipótese 3, segundo a qual o marido será descrito como tendo menos recorrido a todos os tipos de estratégias quando a esposa ganha, é parcialmente verificada. Neste caso, o Paulo recorreu globalmente a menos estratégias de influência (desfecho desconhecido: 4.23; Paulo ganha: 4.16; Luísa ganha: 3.92), $F(2,381)=10.60, p<.001$, e particularmente a menos estratégias de manipulação e de coerção.

A conclusão que se pode retirar desta análise é que se a Luísa não adota um comportamento ativo para impor o seu ponto de vista, é o Paulo que ganha, o que poderá explicar a maior probabilidade de a Luísa recorrer a estratégias de influência quando não se conhece o desfecho da situação de conflito. A argumentação e a negociação parecem ser estratégias particularmente eficazes para as mulheres, e a manipulação e a coerção estratégias eventualmente usadas pelos maridos quando querem ganhar.

\section{Efeito da situação de desacordo}

A interação entre a situação de desacordo, o sexo dos cônjuges e os tipos de estratégias, $F(5,1860)=3.24, p=.006$, revela que a situação em que ocorre o desacordo também modula a avaliação das estratégias utilizadas pelos dois cônjuges. A probabilidade de os cônjuges recorrerem às estratégias de influência consoante a situação de desacordo é descrita no Quadro 5.

A decomposição da interação confirma que a Luísa é vista como o cônjuge que apresenta maior probabilidade de usar as diferentes estratégias de influência em comparação com o Paulo nos dois tipos de desacordo. Existe apenas uma exceção a esta regra: o Paulo terá a mesma probabilidade que a Luísa de utilizar a coerção quando o desacordo incide sobre a escolha entre um carro e um cheque.

A comparação das estratégias usadas pelos cônjuges nas duas situações mostra que a Luísa é vista como tendo uma maior probabilidade de recorrer às estratégias de argumentação quando os cônjuges devem escolher o mobiliário da cozinha do que quando devem optar entre um carro e um cheque, e de utilizar estratégias de negociação e de manipulação quando 
QUADRO 5 - Probabilidade média de os cônjuges recorrerem aos seis tipos de estratégias de influência consoante a situação de desacordo

( 1 = totalmente improvável; 7 = totalmente provável)

\begin{tabular}{|c|c|c|c|c|}
\hline & \multicolumn{2}{|c|}{ Carro } & \multicolumn{2}{|c|}{ Cozinha } \\
\hline & Luísa & Paulo & Luísa & Paulo \\
\hline & \multicolumn{2}{|c|}{$(n=191)$} & \multicolumn{2}{|c|}{$(n=193)$} \\
\hline Argumentação & $5.79 b$ & $5.49 c$ & $5.96 a$ & $5.61 b c$ \\
\hline Negociação & $5.66 a$ & $5.31 \mathrm{c}$ & $5.43 b$ & $5.24 c$ \\
\hline Manipulação & $4.78 a$ & $4.43 b$ & $4.54 b$ & $4.09 c$ \\
\hline Tratamento silencioso & $4.04 a$ & $3.81 b$ & $3.90 a$ & $3.63 b$ \\
\hline Coerção & $3.54 a$ & $3.47 a$ & $3.44 a$ & $3.19 b$ \\
\hline Rebaixamento & $2.76 a$ & $2.58 \mathrm{~b}$ & $2.80 \mathrm{a}$ & $2.38 b$ \\
\hline
\end{tabular}

Nota: em cada linha, letras diferentes indicam médias significativamente diferentes.

devem escolher entre um carro e um cheque, do que quando devem escolher o mobiliário da cozinha. Por sua vez, o Paulo é visto como tendo uma menor probabilidade de recorrer à coerção e à manipulação quando os cônjuges devem escolher o mobiliário da cozinha do que quando devem optar entre um carro e um cheque.

Diferentes estratégias parecem portanto ser utilizadas pelos cônjuges de acordo com a zona de competência em que ocorre o desacordo. Para os homens, quando o assunto faz parte da zona de competência feminina, o objeto de desacordo não justifica recorrer a estratégias manipuladoras ou duras, que são apenas utilizadas em última instância. Para as mulheres, a argumentação servirá na própria zona de competência e a negociação e a manipulação serão vistas como possíveis aliadas para procurar ganhar na zona masculina. Sendo assim, a nossa Hipótese 4, segundo a qual o envolvimento do marido será menor quando a situação de desacordo pertence à zona de competência feminina, é parcialmente verificada.

\section{Motivos subjacentes ao uso das estratégias de influência}

Quanto à questão de saber se o Paulo e a Luísa procuravam, no seu recurso às estratégias de influência, persuadir ou obrigar o parceiro a aceitar a sua escolha, os respondentes consideraram globalmente que os cônjuges procuram mais persuadir do que obrigar (persuadir: 5.66; obrigar: 3.62), $t(383)=22.01, p<.001$. Contudo, existe uma diferença na perceção dos 
motivos dos cônjuges: considerou-se, em apoio à nossa Hipótese 5, que a Luísa procura mais persuadir do que o Paulo (Luísa: 5.83; Paulo: 5.50), $t(383)=4.42, p<.001$, e menos constranger (Luísa: 3.53; Paulo: 3.71), $t(383)=2.36, p=.019$.

Para conhecer os tipos de estratégias aos quais os cônjuges recorrem consoante os motivos que os levam a procurar impor a sua opinião, calculámos as correlações $r$ de Pearson entre a probabilidade de utilizar os vários tipos de estratégias de influência e a vontade de persuadir ou obrigar o parceiro a aceitar a sua escolha. Os valores dos coeficientes de correlação são apresentados no Quadro 6.

QUADRO 6 - Correlações $r$ de Pearson entre a probabilidade de as estratégias serem adotadas e a vontade de persuadir ou obrigar o cônjuge a conformar-se

\begin{tabular}{|c|c|c|c|c|}
\hline & \multicolumn{2}{|c|}{ Persuadir } & \multicolumn{2}{|c|}{ Obrigar } \\
\hline & Luísa & Paulo & Luísa & Paulo \\
\hline & \multicolumn{2}{|c|}{$(n=384)$} & \multicolumn{2}{|c|}{$(n=384)$} \\
\hline Argumentação & $.44 * *$ & $.47^{* * *}$ & .04 & .02 \\
\hline Negociação & $.17 * * *$ & $.15^{* *}$ & .05 & .00 \\
\hline Manipulação & $.33 * * *$ & $.31 * * *$ & $.37 * *$ & $.33 * * *$ \\
\hline Tratamento silencioso & .07 & .09 & $.20 * * *$ & $.20 * * *$ \\
\hline Coerção & $.23 * * *$ & $.21 * * *$ & $.46^{* * *}$ & $.52 * * *$ \\
\hline Rebaixamento & .09 & .06 & $.37 * * *$ & $.32 * * *$ \\
\hline
\end{tabular}

Nota: ${ }^{* *}: p<.001 ;{ }^{* *}: p<.01 ;{ }^{*}: p<.05$

Observa-se, no Quadro 6, uma grande semelhança na perceção das estratégias de influência utilizadas pelos dois cônjuges consoante a intenção que lhes é atribuída. Existem estratégias a que os cônjuges recorrem independentemente da sua vontade de persuadir ou de obrigar: trata-se da manipulação e da coerção. Nota-se, contudo, que a coerção está significativamente mais relacionada com a vontade de obrigar o parceiro do que com a vontade de o persuadir ( $\operatorname{ambos} p<.001)$. Outras estratégias são mais utilizadas quando os cônjuges procuram persuadir o parceiro. Assim a argumentação, sobretudo, e a negociação são tipos de estratégias utilizados para persuadir mas não para obrigar. Por outro lado, existem estratégias mais utilizadas quando os cônjuges procuram mais obrigar do que persuadir: estas são as estratégias de rebaixamento e de tratamento silencioso. 


\section{Conclusão}

Globalmente, os nossos resultados indicam que as estratégias de influência consideradas como as mais frequentemente utilizadas pelos cônjuges são estratégias brandas, que visam não danificar a relação. Não se observam diferenças quanto às preferências atribuídas aos cônjuges no que respeita ao uso destas estratégias. No entanto, os homens consideram as mulheres mais suscetíveis de recorrer a todos os tipos de estratégias, enquanto as mulheres pensam fazer um maior uso de estratégias brandas, apenas.

A argumentação e a negociação são vistas como as armas que permitem às mulheres ganhar quando estão mais motivadas para impor a sua opinião. Dado tratar-se de estratégias de influência bilaterais diretas, este resultado é contrário ao que muitas vezes se refere na literatura, mas é consistente com a atribuição de uma maior intenção de persuadir às mulheres. Por outro lado, a manipulação e a coerção parecem ser estratégias utilizadas pelos maridos, sobretudo quando querem ganhar e/ou quando o desacordo ocorre na sua zona de competência. O recurso a estas últimas estratégias poderá dever-se ao facto de servirem dois propósitos: persuadir e obrigar. Neste sentido, elas poderão contribuir para satisfazer a maior necessidade atribuída aos maridos de ver a sua decisão respeitada, seja pela persuasão, seja pela submissão (Falbo e Peplau, 1980).

A ausência de diferenças relativas aos tipos de estratégias atribuídos aos cônjuges, apesar de contrário ao esperado, poderá ser parcialmente devida a dois fatores: em primeiro lugar, nos nossos cenários os dois cônjuges não se diferenciam em termos de estatuto, o que poderá ter levado os respondentes a inferir uma reciprocidade de comportamentos (Buss et al., 1987; Instone et al., 1983) e não uma utilização, por parte da esposa, das estratégias de influência indiretas mais típicas das mulheres detentoras de menor poder na relação (Weigel et al., 2006). Além disso, o facto de a nossa amostra ter uma maioria de respondentes pertencentes à classe média, relativamente igualitarista (Komter, 1989), poderá também ter induzido uma motivação para negar diferenças nas estratégias atribuídas aos dois cônjuges.

Porém, se não se observam diferenças na perceção dos tipos de estratégias adotados pelos cônjuges, constata-se que as mulheres precisam de recorrer a um maior número de estratégias para conseguir impor a sua opinião, até mesmo na zona de competência tradicionalmente feminina. Com efeito, quando existe um igual esforço dos cônjuges para impor o seu ponto de vista, é o marido quem tem a última palavra. Esta diferença revela, portanto, a posição dominada ocupada pelas mulheres (Aida e Falbo, 1991), uma posição mantida pelos papéis de género tradicionais, em que 
os homens são considerados como os chefes de família e devem ter, por isso, mais poder nas tomadas de decisão (Tichenor, 1999).

A este propósito, é necessário realçar que a relação de poder nos casais heterossexuais surge como uma relação complexa por refletir a ambivalência caraterística das relações entre homens e mulheres (Glick e Fiske, 1997). Se as representações dos papéis conjugais desejáveis continuam a atribuir ao marido o papel de chefe de família, responsável pelas decisões familiares (Poeschl et al., 2004), não há dúvida de que as mulheres também têm preferências e necessidades que desejam ver correspondidas. Tudo indica que, quando estas preferências e necessidades diferem das dos maridos, as mulheres se encontram numa situação desconfortável em que consideram que a aceitação do seu ponto de vista poderá depender de uma utilização normativamente correta das estratégias de influência à sua disposição.

Por último, é importante salientar que o nosso estudo incidiu sobre as representações das estratégias de influência, e não sobre as estratégias efetivamente utilizadas pelos cônjuges. Neste sentido, o estudo não permite avaliar em que medida as respostas recolhidas refletem comportamentos normativos ou comportamentos tidos como ideais. Contudo, considerando que as representações sociais têm a propriedade de orientar os comportamentos, podemos inferir que as mulheres procurarão recorrer às estratégias que representam como adequadas, mas apenas na medida em que tais estratégias não contrariam as posições definidas pelos papéis de género tradicionais, o que contribuirá para a manutenção das desigualdades na família.

\section{Referências bibliográficas}

Aida, Yukie; Falbo, Toni (1991), "Relationships between Marital Satisfaction, Resources, and Power Strategies", Sex Roles, 24, 43-56.

Babcock, Julia C.; Waltz, Jenifer; Jacobsen, Neil S.; Gottman, John M. (1993), "Power and Violence: The Relation between Communication Patterns, Power Discrepancies, and Domestic Violence", Journal of Consulting and Clinical Psychology, 1, 40-50. Blood, Robert O.; Wolfe, Donald M. (1960), Husbands and Wives: The Dynamics of Married Living. New York: The Free Press.

Blumberg, Rae Lesser; Coleman, Marion Tolbert (1989), "A Theoretical Look at the Gender Balance of Power in the American Couple", Journal of Family Issues, 10, 225-250.

Blumstein, Philip; Schwartz, Pepper (1983), American Couples: Money, Work, and Sex. New York: Morrow.

Buss, David M.; Gomes, Mary; Higgins, Dolly S.; Lauterbach, Karen (1987), "Tactics of Manipulation”, Journal of Personality and Social Psychology, 32, 1219-1229. 
Cataldi, Amy E.; Reardon, Richard (1996), "Gender, Interpersonal Orientation, and Manipulation Tactic Use in Close Relationships”, Sex Roles, 35, 205-218.

Cialdini, Robert B. (2001), Influence. Science and Practice. Needham Heights, MA: Allyn $\&$ Bacon [4. ${ }^{\mathrm{a}}$ ed.].

Cromwell, Ronald E.; Olson, David H. (1975), Power in Families. Newbury Park, CA: Sage.

Deutsch, Francine M.; Roksa, Josipa; Meeske, Cynthia (2003), "How Gender Counts when Couples Count their Money”, Sex Roles, 48, 291-304.

Doise, Willem (1985), "Les représentations sociales: définition d'un concept", Connexions, 45, 243-253.

Doise, Willem (1990), “Les représentations sociales”, in Rodolphe Ghiglione; Claude Bonnet; Jean François Richard (orgs.), Traité de psychologie cognitive. Paris: Dunod, 113-174.

Eagly, Alice H. (1995), “The Science of Politics of Comparing Women and Men”, American Psychologist, 50, 145-158.

Falbo, Toni (1977), "Multidimensional Scaling of Power Strategies", Journal of Personality and Social Psychology, 35, 537-547.

Falbo, Toni; Peplau, Letitia Anne (1980), "Power Strategies in Intimate Relationships", Journal of Personality and Social Psychology, 38, 618-628.

Felmlee, Diane H. (1994), "Who's on Top? Power in Romantic Relationships”, Sex Roles, 31, 275-295.

French, John R. P.; Raven, Bertram H. (1959), "The Basis of Power", in Dorwin Cartwright (org.), Studies in Social Power. Ann Arbor, MI: Institute for Social Research, 150-167.

Gagnon, John H.; Simon, William (1973), Sexual Conduct: The Social Sources of Human Sexuality. Chicago: Aldine.

Glick, Peter; Fiske, Susan T. (1997), "Hostile and Benevolent Sexism”, Psychology of Women Quarterly, 21, 119-135.

Gray-Little, Bernadette; Burks, Nancy (1983), "Power and Satisfaction in Marriage: A Review and Critique”, Psychological Bulletin, 93, 513-538.

Hallenbeck, Phyllis N. (1966), "An Analysis of Power Dynamics in Marriage”, Journal of Marriage and the Family, 28, 200-203.

Howard, Judith A.; Blumstein, Philip; Schwartz, Pepper (1986), "Sex, Power, and Influence Tactics in Intimate Relationships", Journal of Personality and Social Psychology, 51, 102-109.

Instone, Debra; Major, Brenda; Bunker, Barbara B. (1983), "Gender, Self-confidence, and Social Influence Strategies: An Organizational Simulation”, Journal of Personality and Social Psychology, 44, 322-333.

Kellerhals, Jean; Troutot, Pierre-Yves; Lazega, Emmanuel (1993), Microsociologie de la famille. Paris: Presses Universitaires de France [2. ${ }^{a}$ ed.].

Komter, Aafke (1989), "Hidden Power in Marriage”, Gender and Society, 3, 187-216. 
Kulik, Liat (1999), "Marital Power Relations, Resources and Gender Role Ideology: A Multivariate Model for Assessing Effects", Journal of Comparative Family Studies, 30, 189-206.

Lukes, Steven (1974), Power: A Radical View. London: Macmillan.

Lukes, Steven (2007), "Power", Contexts, 6, 59-61.

Michel, Andrée (1972), Sociologie de la famille et du mariage. Paris: Presses Universitaires de France.

Moscovici, Serge (1976), La psychanalyse, son image et son public. Paris: Presses Universitaires de France.

Pahl, Jan (1989), Money and Marriage. New York: St. Martin's Press.

Perloff, Richard M. (2003), The Dynamics of Persuasion. Mahwah, NJ: Lawrence Erlbaum [2. ${ }^{\mathrm{a}}$ ed.].

Poeschl, Gabrielle (2000), "Trabalho doméstico e poder familiar: práticas, normas e ideais”, Análise Social, XXXV(156), 695-719.

Poeschl, Gabrielle (2003), “Teoría de las representaciones sociales”, in José Francisco Morales e Carmen Huici (orgs.), Estudios de Psicología Social. Madrid: UNED, 439-466.

Poeschl, Gabrielle; Silva, Aurora; Múrias, Cláudia (2004), "Papéis conjugais desejáveis e traços de personalidade apropriados: uma explicação motivacional", Psicologia e Educação, 3, 121-135.

Rodman, Hyman (1972), "Marital Power and the Theory of Resources in Cultural Context", Journal of Comparative Family Studies, 3, 50-69.

Safilios-Rothschild, Constantina (1970), "The Study of Family Power Structure: A Review 1960-1969", Journal of Marriage and the Family, 31, 290-301.

Sagrestano, Lynda M. (1992), “The Use of Power and Influence in a Gendered World”, Psychology of Women Quarterly, 16, 439-447.

Scanzoni, John (1977), "Changing Sex Roles and Emerging Directions in Family Decision Making”, Journal of Consumer Research, 4, 185-188.

Sexton, Cristine S.; Perlman, Daniel S. (1989), “Couples' Career Orientation, Gender Role Orientation, and Perceived Equity as Determinants of Marital Power”, Journal of Marriage and the Family, 51, 933-941.

Tichenor, Veronica (1999), "Status and Income as Gendered Resources: The Case of Marital Power", Journal of Marriage and the Family, 61, 638-650.

Tichenor, Veronica (2005), "Maintaining Men's Dominance: Negotiating Identity and Power when She Earns More", Sex Roles, 53, 191-205.

Webster, Cynthia (1998), “The Meaning and Measurement of Marital Power: A Review”, Advances in Consumer Research, 25, 395-399.

Weigel, Daniel J.; Bennett, Kymberley K.; Ballard-Reisch, Deborah S. (2006), "Influence Strategies in Marriage: Self and Partner Links between Equity, Strategy Use, and Marital Satisfaction and Commitment", Journal of Family Communication, 6, 77-95. 
Artigo recebido a 01.02.2016

Aprovado para publicação a 19.09.2016

\section{Gabrielle Poeschl}

Faculdade de Psicologia e de Ciências da Educação da Universidade do Porto

Rua Alfredo Allen, 4200-135 Porto, Portugal

Contacto: gpoeschl@fpce.up.pt

\section{Power Relations between Spouses and Social Representations of Influence Strategies amongst Couples}

It is difficult to address the theme of power relationships between couples due to the lack of consensus on the definition of family power and the biases found in studies based on self-reported decision-making. This study, which was developed using a questionnaire with opinion scales, aimed to reveal power relations between couples by examining behavior considered appropriate in situations involving disagreements between couples, requesting 384 married adults of both sexes to indicate the likelihood of a husband and wife using a set of influence strategies when attempting to impose their point of view. The results indicate a preference for soft strategies and great similarity in the strategies adopted by both spouses, but suggest that women need to make greater use of the range of strategies to succeed in influencing their husbands.

Keywords: decision-making; gender representations; influence strategies; marital roles; power relations.

\section{Relation de pouvoir entre conjoints et représentations sociales des stratégies d'influence au sein du couple}

Le rapport de pouvoir au sein du couple est une matière dont l'approche est difficile en vertu de l'absence de consensus quant à la définition du pouvoir familial et des gauchissements constatés dans les études reposant sur des "auto narrations" de prise de décision. Dans une étude conduite en faisant appel à un questionnaire pourvu d'échelons d'opinion, nous avons cherché à mettre en évidence le rapport de pouvoir au sein du couple par le truchement des comportements tenus comme appropriés en cas de désaccord entre conjoints. Pour ce faire, nous avons demandé à 384 adultes mariés des deux sexes d'indiquer qu'elle était la probabilité qu'un mari ou/et qu'une épouse fassent appel à un ensemble de stratégies d'influence lorsqu'ils tentaient d'imposer leur point de vue. Les résultats révèlent une préférence pour les stratégies douce ainsi qu'une grande similitude en matière de stratégies mises en œuvre par les conjoints, mais ils suggèrent que les femmes ont besoin de recourir plus amplement à l'usage des diverses stratégies pour parvenir à influencer leurs maris.

Mots-clés: prise de décision; relations de pouvoir; représentation du genre; rôles conjugaux; stratégies d'influence. 
